International Journal of Applied Mathematics

Volume 29 No. $1 \quad 2016,79-95$

ISSN: $1311-1728$ (printed version); ISSN: 1314-8060 (on-line version)

doi: http://dx.doi.org/10.12732/ijam.v29i1.7

\title{
NUMERICAL SIMULATION OF DRUG RELEASE CORONARY STENTS USING A SEMI DISCRETE SPECTRAL COLLOCATION METHOD
}

\author{
S. Fakhri ${ }^{1}$, S.H. Momeni-Masuleh ${ }^{2}$, M. Hassanpour-Ezatti ${ }^{3}$ \\ $1,2,3$ Department of Mathematics \\ Shahed University \\ Tehran, P.O. Box: 18151-159, IRAN
}

\begin{abstract}
Cardiovascular diseases which include atherosclerosis, are one of the main cause of death in the industrialized world. The most common treatment method for these diseases is a cardiovascular stent. The problem is governed by a set of linear partial differential equations with appropriate boundary conditions. A semi-discrete Chebyshev spectral collocation method aims to find numerical solutions for the reduced unsteady 2-dimension problem of drug release from the stent. The scheme uses the Chebyshev spectral collocation method to approximate the space derivatives and an analytical solution for temporal space. Numerical solutions were carried out on the concentration of the drug in the wall of the tissue. The drug release profile provides important information about its effect on the delivery of therapeutic agents to the vessel wall. For simplicity, one shape of stent and their surrounding normal tissues are selected, and Fick law was employed. The results suggest that the profile of the drug release from the stent has a 2 dimensional hyperbolic shape. Numerical analysis of the error and the rate of convergence of the scheme are also discussed. The proposed scheme is simple to set up, efficient to implement and requires less computational costs than other methods available.
\end{abstract}

AMS Subject Classification: 35K20, 65M20, 65M70, 65C20

Key Words: spectral collocation method, method of lines, semi discrete method, stent, drug release, atherosclerosis

Received: November 18, 2015

(C) 2016 Academic Publications

${ }^{\S}$ Correspondence author 


\section{Introduction}

Atherosclerosis is one of the main cardiovascular diseases which lead to death. It causes a reduction of blood flow in the muscles, tissue and other crucial organs by narrowing or blocking the arteries and may be caused by heart failure. One way to improve the treatment of atherosclerosis and coronary artery disease is to carry out percutaneous transluminal coronary angioplasty surgery and to use cardiovascular stents for release of the anti-thrombus drug of the vessel. Suitable controlled drug delivery depends on many factors, which include the physicochemical properties of the drug, duration of release, and the release profiles [1]. Different mathematical models and numerical simulation techniques have been used for releasing drugs. Hose et al. [9] used a model which explored the use of ANSYS for the model of the process of drug delivery through the vessel wall. Hwang et al. [10] applied the reduced model in cylindrical coordinates by using finite difference method. Varshney et al. [14] used a realistic model, which takes into account the structure of the material that forms the layer of the stent, with a polymeric topcoat to slow down the drug release process from the stent to the artery wall. They applied finite difference method to solve equations for the delivery of drug from a drug eluting stent (DES). Borghi et al. [3] used the finite element approach of a hydrophilic model to release drug from a coronary stent into an arterial wall by adopting an axi-symmetric model of a single stent structure. D'Angelo and Zunino [2] worked on the same model and used non-uniform spacing for the generation of the mesh. In particular, the central section was subdivided by means of variable of tetrahedrons. To solve the governing equations, they applied the commercial solver Fluent based on finite volume schemes. Minicini [12] solved the reduced model by using finite element method. She described various factors that affect the drug release from a DES. Zunino et al. [4] described a model for DES; and they used commercial code ABAQUS/Explicit v: $6: 4^{1}$ to discretize and solve it. Ferreira et al. $[6,7]$ investigated the same model with different parameters and boundary conditions. McGinty and McKee [11] solved this model analytically and compared their results with experimental data via an inverse problem. They attempted to uncouple and estimate both the coefficient of the drug diffusion in the tissue and the convection parameter. In this paper, we are going to solve a reduced realistic model by adopting a spectral collocation method in spatial discretizaton and analytical solution in temporal discretizaton. We used the Gauss-Lobatto points as collocation points and the Chebyshev functions as trial functions. The concentration of drug in the artery wall will be calculated.

\footnotetext{
${ }^{1}$ Simulia Inc., Providence, RI, USA.
} 


\section{Materials and Methods}

\subsection{Governing Equations}

In the modeling of the drug release systems, some of the parameters are more important and more effective. These include [12]:

1. Stent design;

2. Drug properties and textural characteristics;

3. Drug delivery system used as coating of the stent.

The drug release system can be modeled as follows, the reduced system is state for $t \in(0, T)$ :

$$
\begin{array}{r}
\frac{\partial a}{\partial t}+u_{w} \nabla a-D_{w} \Delta a=0, \quad \text { in } \quad \Omega_{w}, \\
D_{w} \frac{\partial a}{\partial n_{w}}+\alpha(t) a=\beta(t) c_{0}, \quad \text { on } \Gamma, \\
D_{w} \frac{\partial a}{\partial n_{w}}+P_{w} \frac{a}{\epsilon_{w} k_{w}}=0, \quad \text { on } \quad \Gamma_{a d v}, \\
a=0, \quad \text { on } \quad \Gamma_{b l} \cup \Gamma_{s} .
\end{array}
$$

Hereafter we will use this as the basic model.

\subsection{Discretization in Space and Time}

\subsubsection{Spatial Discretization using Chebyshev Collocation Method}

In this method, we will use the strong form of Eq. (1). It is implemented by applying Chebyshev functions on Sobolev space $H^{2}$ and using the GaussLobatto points, as follows [5]:

$$
\begin{aligned}
\psi_{l}(x) & =\frac{(-1)^{(l+1)}\left(1-x^{2}\right) T_{N}^{\prime}(x)}{\bar{c}_{l} N^{2}\left(x-x_{l}\right)}, \\
x_{j} & =\cos \left(\frac{\pi j}{N}\right), \quad j=0,1, \ldots, N,
\end{aligned}
$$

where

$$
\bar{c}_{l}= \begin{cases}2, & j=0, N \\ 1, & j=1, \cdots, N-1\end{cases}
$$


It should be noted that the arrangement of the points is $1, \cdots,-1$. This means that they are $x_{0}=1$ and $x_{N}=-1$ and that there are other points between them. The closed forms are the first and second derivative matrices respectively, and they are shown as follows with $\left(D_{N}\right)_{j l}$ and $\left(D_{N}^{(2)}\right)_{j l},[5]$ :

$$
\left(D_{N}\right)_{j l}= \begin{cases}\frac{\bar{c}_{j}}{\bar{c}_{l}} \frac{(-1)^{j+l}}{x_{j_{j}}-x_{l}}, & j \neq l, \\ -\frac{x_{j}}{2\left(1-x_{l}^{2}\right)}, & 1 \leq j=l \leq N-1, \\ \frac{2 N^{2}+1}{6}, & j=l=0, \\ -\frac{2 N^{2}+1}{6}, & j=l=N,\end{cases}
$$

and

$$
\left(D_{N}^{2}\right)_{j l}= \begin{cases}\frac{(-1)^{j+l}}{\bar{c}_{l}} \frac{x_{j}^{2}+x_{j} x_{l}-2}{\left(1-x_{j}^{2}\right)\left(x_{j}-x_{l}\right)^{2}}, & 1 \leq j \leq N-1,0 \leq l \leq N, \\ -\frac{\left(N^{2}-1\right)\left(1-x_{j}^{2}\right)+3}{3\left(1-x_{j}^{2}\right)^{2}}, & j \neq l, \\ \frac{2}{3} \frac{(-1)^{l}}{\bar{c}_{l}} \frac{\left(2 N^{2}+1\right)\left(1-x_{l}\right)-6}{\left(1-x_{l}^{2}\right)}, & j=0,1 \leq l \leq N \\ \frac{2}{3} \frac{(-1)^{l+N}}{\bar{c}_{l}} \frac{\left(2 N^{2}+1\right)\left(1+x_{l}\right)-6}{\left(1+x_{l}^{2}\right)}, & j=N, 0 \leq l \leq N \\ \frac{N^{4}-1}{15}, & j=l=0, j=l=N .\end{cases}
$$

It is worth noting that the Chebyshev polynomials satisfy $D^{2}=D \cdot D$.
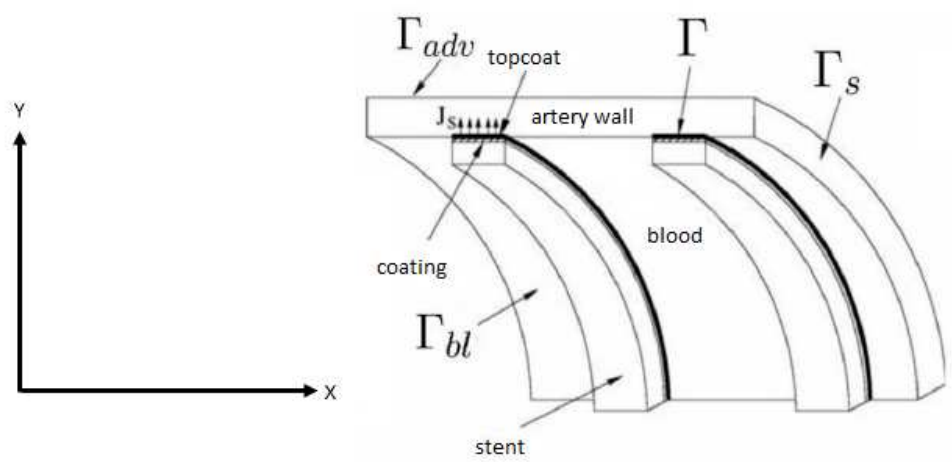

Figure 1: Schematic representation of the stent inside the arterial wall that is covered with the coating uniformly [12].

As shown in Fig. 2, the normal vector on boundaries $\Gamma_{a d v}$ and $\Gamma$ only have components in the direction of the x-axis. Consequently, Eq. (1) states that: 


$$
\frac{\partial a}{\partial t}+\frac{K_{l a g}}{k_{w}}-\frac{k_{b}}{\mu_{b}}\left\{p_{1} \frac{\partial a}{\partial x}+p_{2} \frac{\partial a}{\partial y}\right\}-D_{w}\left\{\frac{\partial^{2} a}{\partial x^{2}}+\frac{\partial^{2} a}{\partial y^{2}}\right\}=0, \quad \text { in } \Omega_{w},
$$

together with the boundary conditions:

$$
\begin{array}{rlrl}
-D_{w} \frac{\partial a}{\partial x}+\alpha(t) a & =\beta(t) c_{0}, & \text { on } \Gamma, \\
-D_{w} \frac{\partial a}{\partial x}+P_{w} \frac{a}{\epsilon_{w} k_{w}} & =0, \quad & \text { on } \Gamma_{a d v}, \\
a & =0, \quad \text { on } \Gamma_{b l} \cup \Gamma_{s} .
\end{array}
$$

Under these circumstances, the concentration function at point $(x, y)$ is:

$$
a(x, y)=\sum_{i=0}^{N} \sum_{j=0}^{N} a_{i j} \psi_{i}(x), \psi_{j}(y),
$$

where

$$
\psi_{i}\left(x_{j}\right)=\delta_{i, j}= \begin{cases}1, & i=j, \\ 0, & i \neq j .\end{cases}
$$

The first and second order partial derivatives of $a$ in the directions of $x$ and $y$ are:

$$
\begin{aligned}
\frac{\partial a}{\partial x} & =\sum_{i=0}^{N} \sum_{j=0}^{N} a_{i j} \psi_{i}^{\prime}(x) \psi_{j}(y), \\
\frac{\partial a}{\partial y} & =\sum_{i=0}^{N} \sum_{j=0}^{N} a_{i j} \psi_{i}(x) \psi_{j}^{\prime}(y), \\
\frac{\partial^{2} a}{\partial x^{2}} & =\sum_{i=0}^{N} \sum_{j=0}^{N} a_{i j} \psi_{i}^{\prime \prime}(x) \psi_{j}(y), \\
\frac{\partial^{2} a}{\partial y^{2}} & =\sum_{i=0}^{N} \sum_{j=0}^{N} a_{i j} \psi_{i}(x) \psi_{j}^{\prime \prime}(y),
\end{aligned}
$$

where the values of $\psi^{\prime}$ and $\psi^{\prime \prime}$ are obtained from component matrices $D_{j l}$ and $D_{j l}^{(2)}$. In order to begin spectral discretization, we considered an XY-cross section of the stent as is shown in Fig. 2. We discretized it into two spatial dimensions. We transferred the physical domain at an interval $[-1,1]$ in each direction, as we used Chebyshev trial functions. Using a convenient transform function, the partial derivatives of $a$ in the direction of $\xi$ and $\eta$ and on the interval $[-1,1]$ are as follows: 


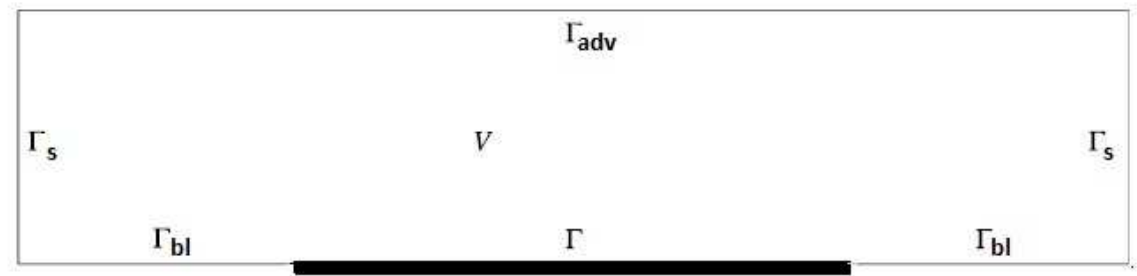

S

Figure 2: XY-Cross Section of the Stent

$$
\begin{aligned}
\frac{\partial a}{\partial x} & =L_{x} \frac{\partial a}{\partial \xi} \\
\frac{\partial a}{\partial y} & =L_{y} \frac{\partial a}{\partial \eta} \\
\frac{\partial^{2} a}{\partial x^{2}} & =L_{x}^{2} \frac{\partial^{2} a}{\partial \xi^{2}} \\
\frac{\partial^{2} a}{\partial y^{2}} & =L_{y}^{2} \frac{\partial^{2} a}{\partial \eta^{2}} .
\end{aligned}
$$

Discretized expansion and partial derivatives of $a$ in terms of Chebyshev expansion functions are given by:

$$
a(\xi, \eta)=\sum_{i=0}^{N_{1}} \sum_{j=0}^{N_{2}} a_{i, j} \psi_{i}(\xi) \psi_{j}(\eta)
$$

where

$$
a_{i, j}=a\left(\xi_{i}, \eta_{j}\right)
$$




$$
\begin{aligned}
\frac{\partial a}{\partial \xi} & =\sum_{i=0}^{N_{1}} \sum_{j=0}^{N_{2}} a_{i, j} \psi_{i}^{\prime}(\xi) \psi_{j}(\eta), \\
\frac{\partial a}{\partial \eta} & =\sum_{i=0}^{N_{1}} \sum_{j=0}^{N_{2}} a_{i, j} \psi_{i}(\xi) \psi_{j}^{\prime}(\eta), \\
\frac{\partial^{2} a}{\partial \xi^{2}} & =\sum_{i=0}^{N_{1}} \sum_{j=0}^{N_{2}} a_{i, j} \psi_{i}^{\prime \prime}(\xi) \psi_{j}(\eta), \\
\frac{\partial^{2} a}{\partial \eta^{2}} & =\sum_{i=0}^{N_{1}} \sum_{j=0}^{N_{2}} a_{i, j} \psi_{i}(\xi) \psi_{j}^{\prime \prime}(\eta) .
\end{aligned}
$$

Thus, Eq. (5) can be written as:

$$
\begin{gathered}
\frac{\partial a}{\partial t}+\frac{K_{l a g}}{K_{w}}-\frac{k_{b}}{\mu_{b}}\left\{p_{1} L_{x} \frac{\partial a}{\partial \xi}+p_{2} L_{y} \frac{\partial a}{\partial \eta}\right\} \\
-D_{w}\left\{L_{x}^{2} \frac{\partial^{2} a}{\partial \xi^{2}}+L_{y}^{2} \frac{\partial^{2} a}{\partial \eta^{2}}\right\}=0, \quad \text { in } \quad \Omega_{w},
\end{gathered}
$$

together with the boundary conditions:

$$
\begin{aligned}
\frac{D_{w}}{L_{y}} \frac{\partial a}{\partial \eta}+\alpha(t) a & =\beta(t) c_{0}, \quad \text { on } \Gamma, \\
\frac{D_{w}}{L_{y}} \frac{\partial a}{\partial \eta}+\frac{P_{w}}{\epsilon_{w} k_{w}} a & =0, \quad \text { on } \Gamma_{a d v}, \\
a & =0, \quad \text { on } \Gamma_{b l} \cup \Gamma_{s} .
\end{aligned}
$$

By replacing discretized relation associated with $a$ and its partial derivatives in Eq. (11) at collocation points $\left(\xi_{p}, \eta_{q}\right)$ and according to Eq. (8), the following 
form can be achieved:

$$
\begin{aligned}
\frac{K_{l a g}}{k_{w}} \frac{k_{b}}{\mu_{b}}\left[p_{1} L_{x}\left\{\sum_{i=0}^{n_{1}} a_{i, q} \psi_{i}^{\prime}\left(\xi_{p}\right)+\sum_{i=n_{1}}^{n_{2}} a_{i, q} \psi_{i}^{\prime}\left(\xi_{p}\right)+\sum_{i=n_{2}+1}^{N 1} a_{i, q} \psi_{i}^{\prime}\left(\xi_{p}\right)\right\}\right. \\
\left.+p_{2} L_{y}\left\{\sum_{j=0}^{N_{2}} a_{p, j} \psi_{j}^{\prime}\left(\eta_{q}\right)\right\}\right] \\
+D_{w}\left[L_{x}^{2}\left\{\sum_{i=0}^{n_{1}} a_{i, q} \psi_{i}^{\prime \prime}\left(\xi_{p}\right)+\sum_{i=n_{1}}^{n_{2}} a_{i, q} \psi_{i}^{\prime \prime}\left(\xi_{p}\right)+\sum_{i=n_{2}+1}^{N 1} a_{i, q} \psi_{i}^{\prime \prime}\left(\xi_{p}\right)\right\}\right. \\
\left.+L_{y}^{2}\left\{\sum_{j=0}^{N_{2}} a_{p, j} \psi_{j}^{\prime \prime}\left(\eta_{q}\right)\right\}\right]=\frac{\partial a}{\partial t}\left(\xi_{p}, \eta_{q}\right),
\end{aligned}
$$

where $p=0,1, \cdots, N_{1}$ and $q=0,1, \cdots, N_{2}$.

In the collocation method, the boundary conditions play a key role in the problem-solving process in general. In this method, we should use the related boundary equations in the boundary points. We now consider the boundary conditions of problem (1). For an XY-cross section of stent, as is shown in Fig. 2, a normal vector only has components in the direction of the $y$-axis. Therefore, we could write the boundary conditions as follows:

$$
\begin{aligned}
-D_{w} \frac{\partial a}{\partial x}+\alpha(t) a & =\beta(t) c_{0}, \quad \text { on } \Gamma, \\
-D_{w} \frac{\partial a}{\partial x}+\frac{P_{w}}{\epsilon_{w} k_{w}} & =0, \quad \text { on } \Gamma_{a d v} .
\end{aligned}
$$

Eqs. (14) and (15) are both first order ordinary differential equations with respect to $x$. Therefore, they can be solved analytically easily. We use these analytical solutions to find the value of $a$ at boundary points. The only unknowns are interior points. By setting the boundary values in problem (5), we will have: 


$$
\begin{aligned}
& \frac{K_{l a g}}{k_{w}} \frac{k_{b}}{\mu_{b}}\left[p_{1} L_{x}\left\{\sum_{i=1}^{n_{1}} a_{i, q} \psi_{i}^{\prime}\left(\xi_{p}\right)+\sum_{i=n_{1}}^{n_{2}} a_{i, q} \psi_{i}^{\prime}\left(\xi_{p}\right)+\sum_{i=n_{2}+1}^{N_{1}-1} a_{i, q} \psi_{i}^{\prime}\left(\xi_{p}\right)\right\}\right. \\
&\left.+p_{2} L_{y}\left\{\sum_{j=1}^{N_{2}-1} a_{p, j} \psi_{j}^{\prime}\left(\eta_{q}\right)\right\}\right] \\
&-D_{w} {\left[L_{x}^{2}\left\{\sum_{i=1}^{n_{1}} a_{i, q} \psi_{i}^{\prime \prime}\left(\xi_{p}\right)+\sum_{i=n_{1}}^{n_{2}} a_{i, q} \psi_{i}^{\prime \prime}\left(\xi_{p}\right)+\sum_{i=n_{2}+1}^{N_{1}-1} a_{i, q} \psi_{i}^{\prime \prime}\left(\xi_{p}\right)\right\}\right.} \\
&+ L_{y}^{2}\left\{\sum_{j=1}^{N_{2}-1} a_{p, j} \psi_{j}^{\prime \prime}\left(\eta_{q}\right)\right\}=\frac{\partial a}{\partial t}\left(\xi_{p}, \eta_{q}\right) \\
&-\frac{K_{l a g}}{k_{w}} \frac{k_{b}}{\mu_{b}}\left[p_{1} L_{x}\left(a_{0, q} \psi_{0}^{\prime}\left(\xi_{p}\right)+a_{N_{1}, q} \psi_{N_{1}}^{\prime}\left(\xi_{p}\right)\right)+\right. \\
&\left.p_{2} L_{y}\left(a_{p, 0} \psi_{0}^{\prime}\left(\eta_{q}\right)+a_{p, N_{2}} \psi_{N_{2}}^{\prime}\left(\eta_{q}\right)\right)\right]
\end{aligned}
$$

where $p=0,1, \cdots, N_{1}$ and $q=0,1, \cdots, N_{2}$.

Eq. (16) is an ordinary differential equation system in terms of time which has $\left(N_{1} \times N_{2}\right) \times\left(N_{1} \times N_{2}\right)$ dimensions of space. Eq. (16) can be written in matrix form as:

$$
\frac{d \mathbf{a}}{d t}=\mathbf{S}+\mathbf{r}
$$

where $\mathbf{S}$ is the coefficient matrix, a is the concentration vector, which is unknown, and $\mathbf{r}$ contains the right-hand side of the system and includes the boundary values.

\subsubsection{Temporal Discretization}

Consider matrix form (17). The analytical solution of this equation is given by $[13]$ :

$$
\mathbf{a}(t)=-\mathbf{S}^{-\mathbf{1}} \mathbf{r}+\left(\mathbf{a}(\mathbf{0})+\mathbf{S}^{-\mathbf{1}} \mathbf{r}\right) e^{\mathbf{t} \mathbf{S}}
$$

Hence,

$$
\mathbf{a}(t+d t)=-\mathbf{S}^{-\mathbf{1}} \mathbf{r}+e^{(t+d t) \mathbf{S}}\left(\mathbf{a}(\mathbf{0})+\mathbf{S}^{-\mathbf{1}} \mathbf{r}\right) .
$$

Inserting Eq. (18) into Eq. (19) yields:

$$
\mathbf{a}(t+d t)=-\mathbf{S}^{-\mathbf{1}} \mathbf{r}+e^{d t \mathbf{S}}\left(\mathbf{a}(\mathbf{t})+\mathbf{S}^{-\mathbf{1}} \mathbf{r}\right) .
$$


Here we use the expm function of MATLAB to approximate the exponential function i.e. $e^{d t \mathbf{S}}$ that works more efficiently than other methods.

\section{Results and Discussion}

In order to demonstrate the accuracy and efficiency of the proposed scheme, we consider the problem of the drug concentration in the artery wall. In the ideal release profile, the release rate is constant within a specified period of time. The most commonly used formulation design strategies employ diffusion and or dissolution as the rate-limiting step. Though, little information exists about the actual drug release from the stent into the vessel wall, generally both mechanisms contribute to the alteration of the release profile. Theoretically, the drug release from a unit dose is governed by Fick's law of diffusion, where the flux of a drug across a surface, such as a stent, is proportional to the concentration gradient of the drug along the diffusion path. The results of our study confirm this. The governing equation, as described previously, is Eq. (11), together with the boundary conditions (14) and (15). The geometric parameters of the stent and artery wall, as well as the diffusion parameters are given in Table 1. The computed mass of drug in the artery wall during the first 7 days are shown in Figs. 3, 4 and 5 for $\Delta t=0.5$ and $N=9, N=18$ and $N=36$, respectively. We may use the computed solution for $N=36$ as a reference that is approximate to the exact solution since it is so accurate when compared with the results other studies and available information. It is therefore possible to

\begin{tabular}{lll}
\hline Parameter Description & Value \\
\hline$K_{\text {lag }}$ & hindrane coefficient & 1 \\
$k_{w}$ & partition coefficient of the drug & 1 \\
$\mu_{b}$ & viscosity of blood plasma & 0.72 \\
& & $10^{-2} \mathrm{gr} / \mathrm{cms}$ \\
$k_{b}$ & hydraulic permeability & $2.0 \times 10^{-14} \mathrm{~cm}^{2}$ \\
$p_{1}$ & pressure & $100 \mathrm{mmHg}$ \\
$p_{2}$ & pressure & $100 \mathrm{~mm} \mathrm{Hg}$ \\
$D_{w}$ & diffusion of coefficient of drug inside tis 2 2 $2 \times 10^{-9} \mathrm{~cm}^{2} / \mathrm{s}$ \\
$\epsilon_{w}$ & porosity of the arterial wall & 0.61 \\
$P_{w}$ & permeability of the tissue & $1 \times 10^{-8}$ \\
\hline
\end{tabular}

Table 1: Parameters of the stent, artery wall and diffusion. 
compare the computed solutions for $N=9$ and $N=18$ with the approximate solution for $N=36$. Tables 3 and 4 represent the absolute error of the scheme by setting the time step $\Delta t=0.5$ between the approximate solution for $N=36$ and the approximate solutions for $N=9$ and $N=18$, respectively. The absolute error between the approximate solutions for $N=9$ and $N=18$ is demonstrated in Table 2. The maximum of absolute error in these tables are in the order of 4, 4 and 7, respectively. As can be seen, the maximum error in all three tables occurs at the hour $k=168$, which indicates that the errors' behavior is the same as the solution. The computed rate of convergence, because of the three different meshes, is in the order of $O\left(h^{13.0}\right)$ where, $h$ is the mesh size. Ferreira [6] and Zunino [4] addressed the behavior of the concentration in the artery wall. Comparisons demonstrate a good agreement between the presented study and their results. However, they used a mesh grid much more than we used in this case.

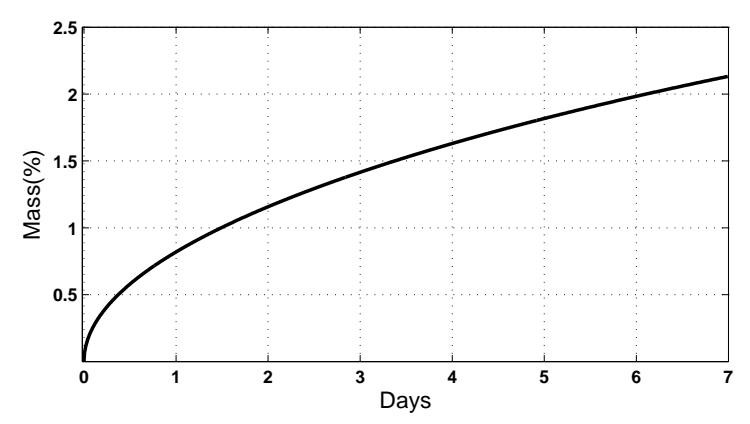

Figure 3: Drug release within the first 7 days with expm function for $\Delta t=0.5$ and $N=9$. 


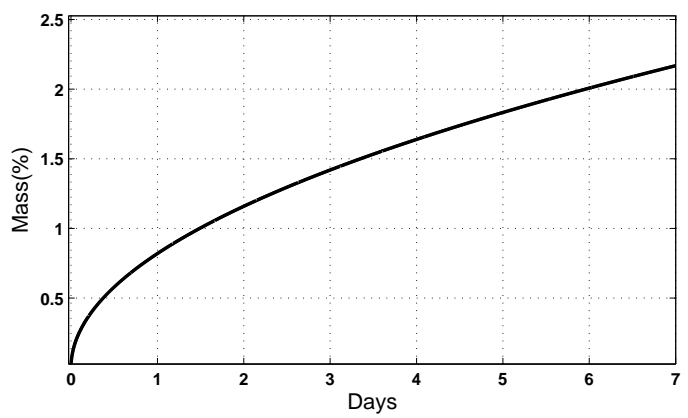

Figure 4: Drug release within the first 7 days with expm function for $\Delta t=0.5$ and $N=18$.

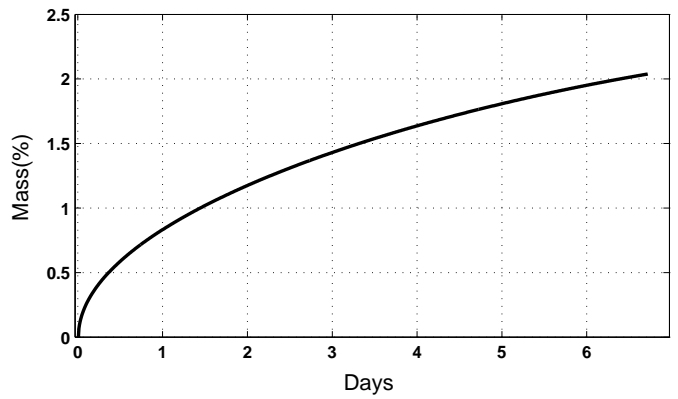

Figure 5: Drug release within the first 7 days with expm function for $\Delta t=0.5$ and $N=36$. 


\begin{tabular}{|c|c|c|c|c|c|c|c|}
\hline $\mathrm{k}$ & Error & $\mathrm{k}$ & Error & $\mathrm{k}$ & Error & $\mathrm{k}$ & Error \\
\hline 1 & $0.000000 \mathrm{e}-00$ & 43 & $5.290431 \mathrm{e}-06$ & 85 & $2.983790 \mathrm{e}-05$ & 127 & $8.204084 \mathrm{e}-05$ \\
\hline 2 & $4.666674 \mathrm{e}-10$ & 44 & $5.610466 \mathrm{e}-06$ & 86 & $3.073215 \mathrm{e}-05$ & 128 & $8.367440 \mathrm{e}-05$ \\
\hline 3 & $2.635921 \mathrm{e}-09$ & 45 & $5.941855 \mathrm{e}-06$ & 87 & $3.164213 \mathrm{e}-05$ & 129 & $8.532730 \mathrm{e}-05$ \\
\hline 4 & $7.258073 \mathrm{e}-09$ & 46 & $6.284723 \mathrm{e}-06$ & 88 & $3.256815 \mathrm{e}-05$ & 130 & $8.699957 \mathrm{e}-05$ \\
\hline 5 & $1.489249 \mathrm{e}-08$ & 47 & $6.639160 \mathrm{e}-06$ & 89 & $3.351019 \mathrm{e}-05$ & 131 & $8.869134 \mathrm{e}-05$ \\
\hline 6 & $2.600632 \mathrm{e}-08$ & 48 & 7.005307e-06 & 90 & $3.446827 \mathrm{e}-05$ & 132 & $9.040229 \mathrm{e}-05$ \\
\hline 7 & $4.100869 \mathrm{e}-08$ & 49 & $7.383290 \mathrm{e}-06$ & 91 & $3.544241 \mathrm{e}-05$ & 133 & $9.213321 \mathrm{e}-05$ \\
\hline 8 & $6.027268 \mathrm{e}-08$ & 50 & $7.773221 \mathrm{e}-06$ & 92 & $3.643315 \mathrm{e}-05$ & 134 & $9.388382 \mathrm{e}-05$ \\
\hline 9 & $8.413779 \mathrm{e}-08$ & 51 & $8.175254 \mathrm{e}-06$ & 93 & $3.744023 \mathrm{e}-05$ & 135 & $9.565421 \mathrm{e}-05$ \\
\hline 10 & $1.129211 \mathrm{e}-07$ & 52 & $8.589521 \mathrm{e}-06$ & 94 & $3.846376 \mathrm{e}-05$ & 136 & $9.744444 \mathrm{e}-05$ \\
\hline 11 & $1.469169 \mathrm{e}-07$ & 53 & $9.016095 \mathrm{e}-06$ & 95 & $3.950373 \mathrm{e}-05$ & 137 & $9.925431 \mathrm{e}-05$ \\
\hline 12 & $1.864083 \mathrm{e}-07$ & 54 & $9.455084 \mathrm{e}-06$ & 96 & $4.056066 \mathrm{e}-05$ & 138 & $1.010841 \mathrm{e}-04$ \\
\hline 13 & $2.316617 \mathrm{e}-07$ & 55 & $1.906652 \mathrm{e}-06$ & 97 & $4.163427 \mathrm{e}-05$ & 139 & $1.029342 \mathrm{e}-04$ \\
\hline 14 & $2.829293 \mathrm{e}-07$ & 56 & $1.037093 \mathrm{e}-05$ & 98 & $4.272464 \mathrm{e}-05$ & 140 & $1.048045 \mathrm{e}-04$ \\
\hline 15 & $3.404604 \mathrm{e}-07$ & 57 & $1.084797 \mathrm{e}-05$ & 99 & $4.383171 \mathrm{e}-05$ & 141 & $1.066950 \mathrm{e}-04$ \\
\hline 16 & $4.044871 \mathrm{e}-07$ & 58 & $1.133790 \mathrm{e}-05$ & 100 & $4.495605 \mathrm{e}-05$ & 142 & $1.086055 \mathrm{e}-04$ \\
\hline 17 & $4.752389 \mathrm{e}-07$ & 59 & $1.184088 \mathrm{e}-05$ & 101 & $4.609738 \mathrm{e}-05$ & 143 & $1.105362 \mathrm{e}-04$ \\
\hline 18 & $5.529280 \mathrm{e}-07$ & 60 & $1.235701 \mathrm{e}-05$ & 102 & $4.725586 \mathrm{e}-05$ & 144 & $1.124875 \mathrm{e}-04$ \\
\hline 19 & $6.377772 \mathrm{e}-07$ & 61 & $1.288636 \mathrm{e}-05$ & 103 & $4.843152 \mathrm{e}-05$ & 145 & $1.144596 \mathrm{e}-04$ \\
\hline 20 & $7.299829 \mathrm{e}-07$ & 62 & $1.342904 \mathrm{e}-05$ & 104 & $4.962490 \mathrm{e}-05$ & 146 & $1.164521 \mathrm{e}-04$ \\
\hline 21 & $8.297471 \mathrm{e}-07$ & 63 & $1.398521 \mathrm{e}-05$ & 105 & $5.083563 \mathrm{e}-05$ & 147 & $1.184650 \mathrm{e}-04$ \\
\hline 22 & $9.372561 \mathrm{e}-07$ & 64 & $1.455498 \mathrm{e}-05$ & 106 & $5.206377 \mathrm{e}-05$ & 148 & $1.204987 \mathrm{e}-04$ \\
\hline 23 & $1.052718 \mathrm{e}-06$ & 65 & $1.513840 \mathrm{e}-05$ & 107 & $5.330924 \mathrm{e}-05$ & 149 & $1.225532 \mathrm{e}-04$ \\
\hline 24 & $1.176308 \mathrm{e}-06$ & 66 & $1.573556 \mathrm{e}-05$ & 108 & $5.457256 \mathrm{e}-05$ & 150 & $1.246286 \mathrm{e}-04$ \\
\hline 25 & $1.308215 \mathrm{e}-06$ & 67 & $1.634669 \mathrm{e}-05$ & 109 & $5.585367 \mathrm{e}-05$ & 151 & $1.267245 \mathrm{e}-04$ \\
\hline 26 & $1.448610 \mathrm{e}-06$ & 68 & $1.697178 \mathrm{e}-05$ & 110 & $5.715256 \mathrm{e}-05$ & 152 & $1.288415 \mathrm{e}-04$ \\
\hline 27 & $1.597657 \mathrm{e}-06$ & 69 & $1.761094 \mathrm{e}-05$ & 111 & $5.846934 \mathrm{e}-05$ & 153 & $1.309798 \mathrm{e}-04$ \\
\hline 28 & $1.755549 \mathrm{e}-06$ & 70 & $1.826439 \mathrm{e}-05$ & 112 & $5.980427 \mathrm{e}-05$ & 154 & $1.331393 \mathrm{e}-04$ \\
\hline 29 & $1.922432 \mathrm{e}-06$ & 71 & $1.893210 \mathrm{e}-05$ & 113 & $6.115742 \mathrm{e}-05$ & 155 & $1.353197 \mathrm{e}-04$ \\
\hline 30 & $2.098478 \mathrm{e}-06$ & 72 & $1.961416 \mathrm{e}-05$ & 114 & $6.252850 \mathrm{e}-05$ & 156 & $1.375212 \mathrm{e}-04$ \\
\hline 31 & $2.283834 \mathrm{e}-06$ & 73 & $2.031087 \mathrm{e}-05$ & 115 & $6.391769 \mathrm{e}-05$ & 157 & $1.397442 \mathrm{e}-04$ \\
\hline 32 & $2.478688 \mathrm{e}-06$ & 74 & $2.102202 \mathrm{e}-05$ & 116 & $6.532512 \mathrm{e}-05$ & 158 & $1.419885 \mathrm{e}-04$ \\
\hline 33 & $2.683173 \mathrm{e}-06$ & 75 & $2.174791 \mathrm{e}-05$ & 117 & $6.675128 \mathrm{e}-05$ & 159 & $1.442541 \mathrm{e}-04$ \\
\hline 34 & $2.897453 \mathrm{e}-06$ & 76 & $2.248866 \mathrm{e}-05$ & 118 & $6.819594 \mathrm{e}-05$ & 160 & $1.465412 \mathrm{e}-04$ \\
\hline 35 & $3.121666 \mathrm{e}-06$ & 77 & $2.324435 \mathrm{e}-05$ & 119 & $6.965917 \mathrm{e}-04$ & 161 & $1.488501 \mathrm{e}-04$ \\
\hline 36 & $3.355959 \mathrm{e}-06$ & 78 & $2.401502 \mathrm{e}-05$ & 120 & $7.114091 \mathrm{e}-05$ & 162 & $1.511809 \mathrm{e}-04$ \\
\hline 37 & $3.600490 \mathrm{e}-06$ & 79 & $2.480077 \mathrm{e}-05$ & 121 & $7.264106 \mathrm{e}-05$ & 163 & $1.535330 \mathrm{e}-04$ \\
\hline 38 & $3.855392 \mathrm{e}-06$ & 80 & $2.560169 \mathrm{e}-05$ & 122 & $7.416031 \mathrm{e}-05$ & 164 & $1.559069 \mathrm{e}-04$ \\
\hline 39 & $4.120822 \mathrm{e}-06$ & 81 & $2.641797 \mathrm{e}-05$ & 123 & $7.569844 \mathrm{e}-05$ & 165 & $1.583026 \mathrm{e}-04$ \\
\hline 40 & $4.396907 \mathrm{e}-06$ & 82 & $2.724963 \mathrm{e}-05$ & 124 & $7.725552 \mathrm{e}-05$ & 166 & $1.607203 \mathrm{e}-04$ \\
\hline 41 & $4.683778 \mathrm{e}-06$ & 83 & $2.809676 \mathrm{e}-05$ & 125 & $7.883161 \mathrm{e}-05$ & 167 & $1.631599 \mathrm{e}-04$ \\
\hline 42 & $4.981569 \mathrm{e}-06$ & 84 & $2.895954 \mathrm{e}-05$ & 126 & $8.042664 \mathrm{e}-05$ & 168 & $1.656213 \mathrm{e}-04$ \\
\hline
\end{tabular}

Table 2: The absolute error of mass drug using the scheme for $N=9,18$ within the first 168 hours. 


\begin{tabular}{|c|c|c|c|c|c|c|c|}
\hline $\mathrm{k}$ & Error & $\mathrm{k}$ & Error & $\mathrm{k}$ & Error & $\mathrm{k}$ & Error \\
\hline 1 & $0.000000 \mathrm{e}-00$ & 43 & $5.291052 \mathrm{e}-06$ & 85 & $2.984140 \mathrm{e}-05$ & 127 & $8.205046 \mathrm{e}-05$ \\
\hline 2 & $4.667189 \mathrm{e}-10$ & 44 & $5.611126 \mathrm{e}-06$ & 86 & $3.073575 \mathrm{e}-05$ & 128 & $8.368421 \mathrm{e}-05$ \\
\hline 3 & $2.636213 \mathrm{e}-09$ & 45 & $5.942556 \mathrm{e}-06$ & 87 & $3.164585 \mathrm{e}-05$ & 129 & $8.533729 \mathrm{e}-05$ \\
\hline 4 & $7.258926 \mathrm{e}-09$ & 46 & $6.285458 \mathrm{e}-06$ & 88 & $3.257196 \mathrm{e}-05$ & 130 & $8.700977 \mathrm{e}-05$ \\
\hline 5 & $1.489423 \mathrm{e}-08$ & 47 & $6.639927 \mathrm{e}-06$ & 89 & $3.351412 \mathrm{e}-05$ & 131 & $8.870172 \mathrm{e}-05$ \\
\hline 6 & $2.600941 \mathrm{e}-08$ & 48 & $7.006118 \mathrm{e}-06$ & 90 & $3.447231 \mathrm{e}-05$ & 132 & $9.041289 \mathrm{e}-05$ \\
\hline 7 & $4.101371 \mathrm{e}-08$ & 49 & $7.384144 \mathrm{e}-06$ & 91 & $3.544656 \mathrm{e}-05$ & 133 & $9.214402 \mathrm{e}-05$ \\
\hline 8 & $6.028047 \mathrm{e}-08$ & 50 & $7.774120 \mathrm{e}-06$ & 92 & $3.643740 \mathrm{e}-05$ & 134 & $9.389481 \mathrm{e}-05$ \\
\hline 9 & $8.414804 \mathrm{e}-08$ & 51 & $8.176200 \mathrm{e}-06$ & 93 & $3.744460 \mathrm{e}-05$ & 135 & $9.566541 \mathrm{e}-05$ \\
\hline 10 & $1.129350 \mathrm{e}-07$ & 52 & $8.590515 \mathrm{e}-06$ & 94 & $3.846825 \mathrm{e}-05$ & 136 & $9.745585 \mathrm{e}-05$ \\
\hline 11 & $1.469349 \mathrm{e}-07$ & 53 & $9.017140 \mathrm{e}-06$ & 95 & $3.950834 \mathrm{e}-05$ & 137 & $9.926593 \mathrm{e}-05$ \\
\hline 12 & $1.864311 \mathrm{e}-07$ & 54 & $9.456180 \mathrm{e}-06$ & 96 & $4.056540 \mathrm{e}-05$ & 138 & $1.010959 \mathrm{e}-04$ \\
\hline 13 & $2.316895 \mathrm{e}-07$ & 55 & $9.907798 \mathrm{e}-06$ & 97 & $4.163914 \mathrm{e}-05$ & 139 & $1.029463 \mathrm{e}-04$ \\
\hline 14 & $2.829634 \mathrm{e}-07$ & 56 & $1.037213 \mathrm{e}-05$ & 98 & $4.272964 \mathrm{e}-05$ & 140 & $1.048168 \mathrm{e}-04$ \\
\hline 15 & $3.405008 \mathrm{e}-07$ & 57 & $1.084922 \mathrm{e}-05$ & 99 & $4.383684 \mathrm{e}-05$ & 141 & $1.067075 \mathrm{e}-04$ \\
\hline 16 & $4.045349 \mathrm{e}-07$ & 58 & $1.133921 \mathrm{e}-05$ & 100 & $4.496131 \mathrm{e}-05$ & 142 & $1.086182 \mathrm{e}-04$ \\
\hline 17 & $4.752952 \mathrm{e}-07$ & 59 & $1.184225 \mathrm{e}-05$ & 101 & $4.610277 \mathrm{e}-05$ & 143 & $1.105492 \mathrm{e}-04$ \\
\hline 18 & $5.529935 \mathrm{e}-07$ & 60 & $1.235844 \mathrm{e}-05$ & 102 & $4.726138 \mathrm{e}-05$ & 144 & $1.125007 \mathrm{e}-04$ \\
\hline 19 & $6.378525 \mathrm{e}-07$ & 61 & $1.288785 \mathrm{e}-05$ & 103 & $4.843719 \mathrm{e}-05$ & 145 & $1.144730 \mathrm{e}-04$ \\
\hline 20 & $7.300695 \mathrm{e}-07$ & 62 & $1.343060 \mathrm{e}-05$ & 104 & $4.963070 \mathrm{e}-05$ & 146 & $1.164658 \mathrm{e}-04$ \\
\hline 21 & $8.298453 \mathrm{e}-07$ & 63 & $1.398683 \mathrm{e}-05$ & 105 & $5.084258 \mathrm{e}-05$ & 147 & $1.184789 \mathrm{e}-04$ \\
\hline 22 & $9.373675 \mathrm{e}-07$ & 64 & $1.455667-\mathrm{e} 05$ & 106 & $5.206986 \mathrm{e}-05$ & 148 & $1.205128 \mathrm{e}-04$ \\
\hline 23 & $1.052843 \mathrm{e}-06$ & 65 & $1.514015 \mathrm{e}-05$ & 107 & $5.331548 \mathrm{e}-05$ & 149 & $1.225676 \mathrm{e}-04$ \\
\hline 24 & $1.176449 \mathrm{e}-06$ & 66 & $1.573739 \mathrm{e}-05$ & 108 & $5.457896 \mathrm{e}-05$ & 150 & $1.246432 \mathrm{e}-04$ \\
\hline 25 & $1.308371 \mathrm{e}-06$ & 67 & $1.634859 \mathrm{e}-05$ & 109 & $5.586021 \mathrm{e}-05$ & 151 & $1.267393 \mathrm{e}-04$ \\
\hline 26 & $1.448784 \mathrm{e}-06$ & 68 & $1.697375 \mathrm{e}-05$ & 110 & $5.715926 \mathrm{e}-05$ & 152 & $1.288566 \mathrm{e}-04$ \\
\hline 27 & $1.597848 \mathrm{e}-06$ & 69 & $1.761298 \mathrm{e}-05$ & 111 & $5.847618 \mathrm{e}-05$ & 153 & $1.309951 \mathrm{e}-04$ \\
\hline 28 & $1.755758 \mathrm{e}-06$ & 70 & $1.826651 \mathrm{e}-05$ & 112 & $5.981126 \mathrm{e}-05$ & 154 & $1.331549 \mathrm{e}-04$ \\
\hline 29 & $1.922661 \mathrm{e}-06$ & 71 & $1.893430 \mathrm{e}-05$ & 113 & $6.116458 \mathrm{e}-05$ & 155 & $1.353356 \mathrm{e}-04$ \\
\hline 30 & $2.098726 \mathrm{e}-06$ & 72 & $1.961643 \mathrm{e}-05$ & 114 & $6.253582 \mathrm{e}-05$ & 156 & $1.375373 \mathrm{e}-04$ \\
\hline 31 & $2.498982 \mathrm{e}-06$ & 73 & $2.031323 \mathrm{e}-05$ & 115 & $6.392517 \mathrm{e}-05$ & 157 & $1.397606 \mathrm{e}-04$ \\
\hline 32 & $2.683490 \mathrm{e}-06$ & 74 & $2.102446 \mathrm{e}-05$ & 116 & $6.533277 \mathrm{e}-05$ & 158 & $1.420052 \mathrm{e}-04$ \\
\hline 33 & $2.897794 \mathrm{e}-06$ & 75 & $2.175044 \mathrm{e}-05$ & 117 & $6.675909 \mathrm{e}-05$ & 159 & $1.442710 \mathrm{e}-04$ \\
\hline 34 & $3.414260 \mathrm{e}-06$ & 76 & $2.249128 \mathrm{e}-05$ & 118 & $6.820394 \mathrm{e}-05$ & 160 & $1.465583 \mathrm{e}-04$ \\
\hline 35 & $3.122033 \mathrm{e}-06$ & 77 & $2.324706 \mathrm{e}-05$ & 119 & $6.966733 \mathrm{e}-05$ & 161 & $1.488675 \mathrm{e}-04$ \\
\hline 36 & $3.356354 \mathrm{e}-06$ & 78 & $2.401781 \mathrm{e}-05$ & 120 & $7.114923 \mathrm{e}-05$ & 162 & $1.511986 \mathrm{e}-04$ \\
\hline 37 & $3.600914 \mathrm{e}-06$ & 79 & $2.480367 \mathrm{e}-05$ & 121 & $7.264957 \mathrm{e}-05$ & 163 & $1.535511 \mathrm{e}-04$ \\
\hline 38 & $3.855846 \mathrm{e}-06$ & 80 & $2.560469 \mathrm{e}-05$ & 122 & $7.416900 \mathrm{e}-05$ & 164 & $1.559251 \mathrm{e}-04$ \\
\hline 39 & $4.121306 \mathrm{e}-06$ & 81 & $2.642106 \mathrm{e}-05$ & 123 & $7.570731 \mathrm{e}-05$ & 165 & $1.583211 \mathrm{e}-04$ \\
\hline 40 & $4.397424 \mathrm{e}-06$ & 82 & $2.725281 \mathrm{e}-05$ & 124 & $7.726458 \mathrm{e}-05$ & 166 & $1.607392 \mathrm{e}-04$ \\
\hline 41 & $4.684330 \mathrm{e}-06$ & 83 & $2.810005 \mathrm{e}-05$ & 125 & $7.884085 \mathrm{e}-05$ & 167 & $1.631790 \mathrm{e}-04$ \\
\hline 42 & $4.982156 \mathrm{e}-06$ & 84 & $2.896293 \mathrm{e}-05$ & 126 & $8.043606 \mathrm{e}-05$ & 168 & $1.656408 \mathrm{e}-04$ \\
\hline
\end{tabular}

Table 3: The absolute error of mass drug using the scheme for $N=9,36$ within the first 168 hours. 


\begin{tabular}{|c|c|c|c|c|c|c|c|}
\hline $\mathrm{k}$ & Error & $\mathrm{k}$ & Error & $\mathrm{k}$ & Error & $\mathrm{k}$ & Error \\
\hline 1 & $0.000000 \mathrm{e}-00$ & 43 & $6.210736 \mathrm{e}-10$ & 85 & $3.495508 \mathrm{e}-09$ & 127 & $9.617503 \mathrm{e}-09$ \\
\hline 2 & $5.148312 \mathrm{e}-14$ & 44 & $6.597762 \mathrm{e}-10$ & 86 & $3.601141 \mathrm{e}-09$ & 128 & $9.805906 \mathrm{e}-09$ \\
\hline 3 & $2.916903 \mathrm{e}-13$ & 45 & $7.006126 \mathrm{e}-10$ & 87 & $3.713292 \mathrm{e}-09$ & 129 & $9.995800 \mathrm{e}-09$ \\
\hline 4 & $8.525264 \mathrm{e}-13$ & 46 & $7.357708 \mathrm{e}-10$ & 88 & $3.816497 \mathrm{e}-09$ & 130 & $1.019212 \mathrm{e}-08$ \\
\hline 5 & $1.742342 \mathrm{e}-12$ & 47 & $7.676938 \mathrm{e}-10$ & 89 & $3.927443 \mathrm{e}-09$ & 131 & $1.038311 \mathrm{e}-08$ \\
\hline 6 & $3.087884 \mathrm{e}-12$ & 48 & $8.113657 \mathrm{e}-10$ & 90 & $4.036518 \mathrm{e}-09$ & 132 & $1.059867 \mathrm{e}-08$ \\
\hline 7 & $5.021733 \mathrm{e}-12$ & 49 & $8.537305 \mathrm{e}-10$ & 91 & $4.148636 \mathrm{e}-09$ & 133 & $1.080898 \mathrm{e}-08$ \\
\hline 8 & 7.791753e-12 & 50 & $8.991421 \mathrm{e}-10$ & 92 & $4.253878 \mathrm{e}-09$ & 134 & $1.099609 \mathrm{e}-08$ \\
\hline 9 & $1.025506 \mathrm{e}-11$ & 51 & $9.458951 \mathrm{e}-10$ & 93 & $4.369471 \mathrm{e}-09$ & 135 & $1.120777 \mathrm{e}-08$ \\
\hline 10 & $1.398748 \mathrm{e}-11$ & 52 & $9.930958 \mathrm{e}-10$ & 94 & $4.495642 \mathrm{e}-09$ & 136 & $1.141420 \mathrm{e}-08$ \\
\hline 11 & $1.801710 \mathrm{e}-11$ & 53 & $1.044453 \mathrm{e}-09$ & 95 & $4.614996 \mathrm{e}-09$ & 137 & $1.161521 \mathrm{e}-08$ \\
\hline 12 & $2.285663 \mathrm{e}-11$ & 54 & $1.095320 \mathrm{e}-09$ & 96 & $4.742470 \mathrm{e}-09$ & 138 & $1.183510 \mathrm{e}-08$ \\
\hline 13 & $2.778078 \mathrm{e}-11$ & 55 & $1.145592 \mathrm{e}-09$ & 97 & $4.865470 \mathrm{e}-09$ & 139 & $1.205573 \mathrm{e}-08$ \\
\hline 14 & $3.402774 \mathrm{e}-11$ & 56 & $1.200163 \mathrm{e}-09$ & 98 & $4.999212 \mathrm{e}-09$ & 140 & $1.226482 \mathrm{e}-08$ \\
\hline 15 & $4.037393 \mathrm{e}-11$ & 57 & $1.257136 \mathrm{e}-09$ & 99 & $5.125904 \mathrm{e}-09$ & 141 & $1.249308 \mathrm{e}-08$ \\
\hline 16 & $4.777291 \mathrm{e}-11$ & 58 & $1.314525 \mathrm{e}-09$ & 100 & $5.255796 \mathrm{e}-09$ & 142 & $1.272805 \mathrm{e}-08$ \\
\hline 17 & $5.628470 \mathrm{e}-11$ & 59 & $1.373366 \mathrm{e}-09$ & 101 & $5.394047 \mathrm{e}-09$ & 143 & $1.293920 \mathrm{e}-08$ \\
\hline 18 & $6.557518 \mathrm{e}-11$ & 60 & $1.431628 \mathrm{e}-09$ & 102 & $5.527756 \mathrm{e}-09$ & 144 & $1.317577 \mathrm{e}-08$ \\
\hline 19 & $7.538280 \mathrm{e}-11$ & 61 & $1.494410 \mathrm{e}-09$ & 103 & $5.667305 \mathrm{e}-09$ & 145 & $1.340690 \mathrm{e}-08$ \\
\hline 20 & $8.655550 \mathrm{e}-11$ & 62 & $1.555666 \mathrm{e}-09$ & 104 & $5.802217 \mathrm{e}-09$ & 146 & $1.363241 \mathrm{e}-08$ \\
\hline 21 & $9.829512 \mathrm{e}-11$ & 63 & $1.620383 \mathrm{e}-09$ & 105 & $5.953717 \mathrm{e}-09$ & 147 & $1.387119 \mathrm{e}-08$ \\
\hline 22 & $1.114777 \mathrm{e}-10$ & 64 & $1.685560 \mathrm{e}-09$ & 106 & $6.095040 \mathrm{e}-09$ & 148 & $1.409819 \mathrm{e}-08$ \\
\hline 23 & $1.252450 \mathrm{e}-10$ & 65 & $1.754137 \mathrm{e}-09$ & 107 & $6.237005 \mathrm{e}-09$ & 149 & $1.435108 \mathrm{e}-08$ \\
\hline 24 & $1.405367 \mathrm{e}-10$ & 66 & $1.827559 \mathrm{e}-09$ & 108 & $6.393079 \mathrm{e}-09$ & 150 & $1.460490 \mathrm{e}-08$ \\
\hline 25 & $1.564685 \mathrm{e}-10$ & 67 & $1.895183 \mathrm{e}-09$ & 109 & $6.541720 \mathrm{e}-09$ & 151 & $1.483433 \mathrm{e}-08$ \\
\hline 26 & $1.737175 \mathrm{e}-10$ & 68 & $1.973874 \mathrm{e}-09$ & 110 & $6.696406 \mathrm{e}-09$ & 152 & $1.507692 \mathrm{e}-08$ \\
\hline 27 & $1.912329 \mathrm{e}-10$ & 69 & $2.044582 \mathrm{e}-09$ & 111 & $6.843538 \mathrm{e}-09$ & 153 & $1.533938 \mathrm{e}-08$ \\
\hline 28 & $2.093561 \mathrm{e}-10$ & 70 & $2.044582 \mathrm{e}-09$ & 112 & $6.996547 \mathrm{e}-09$ & 154 & $1.557708 \mathrm{e}-08$ \\
\hline 29 & $2.291625 \mathrm{e}-10$ & 71 & $2.200253 \mathrm{e}-09$ & 113 & $7.158500 \mathrm{e}-09$ & 155 & $1.584106 \mathrm{e}-08$ \\
\hline 30 & $2.482149 \mathrm{e}-10$ & 72 & $2.276690 \mathrm{e}-09$ & 114 & 7.321045e-09 & 156 & $1.609297 \mathrm{e}-08$ \\
\hline 31 & $2.700666 \mathrm{e}-10$ & 73 & $2.360171 \mathrm{e}-09$ & 115 & $7.481570 \mathrm{e}-09$ & 157 & $1.637156 \mathrm{e}-08$ \\
\hline 32 & $2.936278 \mathrm{e}-10$ & 74 & $2.444199 \mathrm{e}-09$ & 116 & 7.653911e-09 & 158 & $1.664456 \mathrm{e}-08$ \\
\hline 33 & $3.168017 \mathrm{e}-10$ & 75 & $2.528795 \mathrm{e}-09$ & 117 & $7.807217 \mathrm{e}-09$ & 159 & $1.689881 \mathrm{e}-08$ \\
\hline 34 & $3.414260 \mathrm{e}-10$ & 76 & $2.616143 \mathrm{e}-09$ & 118 & $8.000610 \mathrm{e}-09$ & 160 & $1.717320 \mathrm{e}-08$ \\
\hline 35 & $3.678438 \mathrm{e}-10$ & 77 & $2.706259 \mathrm{e}-09$ & 119 & $8.163793 \mathrm{e}-09$ & 161 & $1.742894 \mathrm{e}-08$ \\
\hline 36 & $3.948620 \mathrm{e}-10$ & 78 & 2.792372e-09 & 120 & $8.316238 \mathrm{e}-09$ & 162 & $1.771152 \mathrm{e}-08$ \\
\hline 37 & $4.243235 \mathrm{e}-10$ & 79 & $2.901869 \mathrm{e}-09$ & 121 & $8.511800 \mathrm{e}-09$ & 163 & $1.800826 \mathrm{e}-08$ \\
\hline 38 & $4.541623 \mathrm{e}-10$ & 80 & $2.995990 \mathrm{e}-09$ & 122 & $8.693868 \mathrm{e}-09$ & 164 & $1.826611 \mathrm{e}-08$ \\
\hline 39 & $4.843538 \mathrm{e}-10$ & 81 & $3.092962 \mathrm{e}-09$ & 123 & $8.870904 \mathrm{e}-09$ & 165 & $1.855107 \mathrm{e}-08$ \\
\hline 40 & $5.173383 \mathrm{e}-10$ & 82 & $3.188123 \mathrm{e}-09$ & 124 & $9.057319 \mathrm{e}-09$ & 166 & $1.887030 \mathrm{e}-08$ \\
\hline 41 & $5.515308 \mathrm{e}-10$ & 83 & $3.293213 \mathrm{e}-09$ & 125 & $9.238525 \mathrm{e}-09$ & 167 & $1.911012 \mathrm{e}-08$ \\
\hline 42 & $5.869117 \mathrm{e}-10$ & 84 & 3.391866e-09 & 126 & $9.426189 \mathrm{e}-09$ & 168 & $1.943105 \mathrm{e}-08$ \\
\hline
\end{tabular}

Table 4: The absolute error of mass drug using the scheme for $N=18,36$ within the first 168 hours. 


\section{References}

[1] G. Acharya, K. Park, Mechanisms of controlled drug release from drugeluting stents, Adv. Drug Deliv. Rev., 3 (2008), 387-401.

[2] C. D'Angelo, P. Zunino, A numerical study of the interaction of blood flow and drug release from cardiovascular stents, Numer. Math. Adv. Appl., 8 (2008), 75-82.

[3] A. Borghi, E. Foa, R. Balossino, F. Migliavacca, G. Dubini, Modelling drug elution from stents: effects of reversible binding in the vascular wall and degradable polymeric matrix, Comput. Methods. Biomech. Bio. Engrg., 4 (2008), 367-377.

[4] P. Zunino, C. D'Angelo, L. Petrini, C. Vergara, C. Capelli, F. Migliavacca, Numerical simulation of drug eluting coronary stents: Mechanics, fluid dynamics and drug release, Comput. Methods Appl. Mech. Engrg 198 (2009), 3633-3644.

[5] C. Canuto, M. Y. Hussaini, A. Quarteroni, T. A. Zang, Spectral Method: Fundamental in Single Domain, Springer-Verlag, New York (2006).

[6] J.A. Ferreira, J. Naghipoor, P. de Oliveira, Numerical simulation of a coupled cardiovascular drug delivery model, In: Comp. Math. Methods. Sci. Engrg, (2013), 642-653.

[7] J.A. Ferreira, J. Naghipoor, P. de Oliveira, Analytical and numerical study of a coupled cardiovascular drug delivery model, J. Comp. Appl. Math., 19 (2014), 664-673.

[8] J.S. Hesthaven, S. Gottlieb, D. Gottlieb, Spectral Method for Timedependent Problems, Cambridge Univ. Press (2007).

[9] D.R. Hose, B. Griffiths, S. Mahmood, J. Gun, D. Sweene, J. Kelly, P.V. Lawford, Modelling drug delivery from stents using ANSYS, Ctr. R., 133 (2009), 24-30.

[10] C.W. Hwang, D. Wu, E.R. Edelman, Physiological transport forces govern drug distribution for stent-based delivery, J. Circulation, 104 (2001), 600605.

[11] S. McGinty, S. McKee, C. McCormick, M. Wheel, Release mechanism and parameter estimation in drug-eluting stent systems: Analytical solutions of drug release and tissue transport, Math. Med. Bio., 32 (2014), 163-186. 
[12] S. Minicini, Mathematical and Numerical Modeling of Controlled Drug Release, Ph.D Thesis, Politecnico di Milano, Italy (2009).

[13] G.D. Smith, Numerical Solution of Partial Differential Equations: Finite Difference Methods, Oxford University Press (1985).

[14] G. Varshney, V.K. Katiyar, S. Kumar, Mathematical modeling and numerical simulation of drug release in stended artery, Appl. Math. Mech., 4 (2008), 91-102. 
